\title{
Curriculum Renewal: Barriers to Successful Curriculum Change and Suggestions for Improvement
}

\author{
Trudi Cooper \\ Correspondence: Trudi Cooper, School of Arts and Humanities, Edith Cowan University, 270, Joondalup Dr, Joondalup, \\ Western Australia, 6027, Australia.
}

Received: September 24, 2017

Accepted: October 21, $2017 \quad$ Online Published: October 25, 2017

doi:10.11114/jets.v5i11.2737

URL: https://doi.org/10.11114/jets.v5i11.2737

\begin{abstract}
This article examines the practical difficulties encountered when a renewed curriculum is implemented in higher education. Attention has been given in the literature to the importance of coherent curriculum and approaches to curriculum design. Less attention has been paid to whether the renewed curriculum can be faithfully implemented within a given university context and how constraints to implementation change the curriculum design. Practical barriers to implementation arose from several sources. These included: how to ensure that all staff understood and supported the new approaches, in the context of a casualized academic workforce; the need for academics to find sufficient time to engage with the renewal process and complete the necessary work to implement the new curriculum, in the context of intensification of academic work; how to support academic staff to gain an understanding of curriculum design changes in a context where few staff have formally studied education; and, the tension between explicit curriculum philosophies that inform alternative curriculum designs and tacit curriculum philosophies embedded in university systems. The project used an action-learning approach and situated the learning in the context of literature on curriculum, academic work and contemporary university practices, to draw conclusions about how universities can better support successful implementation of curriculum change. The article concludes that successful realisation of curriculum change requires on-going support from management and a flexible environment to ensure that planned changes can be implemented effectively. This has implications for many university systems including, academic support, professional development, academic workloads, and university reporting systems.
\end{abstract}

Keywords: curriculum, higher education, academic work, university management, teaching and learning, renewal, change management, Threshold Concepts, workloads, Barnett and Coate

\section{Introduction and Background}

The impetus for this article came from the practical realisation that the initial phase of curriculum redesign was relatively straightforward, but that successful implementation of a renewed curriculum was much more challenging. Barnett and Coate (2005) refer to this as the difference between the curriculum-as-designed and the curriculum-as-enacted. To ensure that renewed curriculum actually changes teaching and learning practices and is not merely a paper exercise, it is important to understand and overcome barriers to successful implementation of curriculum change in higher education. The central questions addressed in the article are 1) what are the barriers to curriculum change and 2) how could processes and practices be improved in universities to support curriculum change better. Improved knowledge of barriers to implementation clarifies how such support can be provided most effectively. This article discusses the implementation process at one institution, and relates the experience to the academic literature on practices in Australian universities and elsewhere, to contextualise the findings and allow judgement about the broader applicability of the learning from this project.

In 2010, I gained funding to lead an Australian national university curriculum renewal project for youth work education funded by the Australian Learning and Teaching Council (ALTC/OLT) (Cooper, Bessant, Broadbent, Couch, \& Edwards, 2014). A purpose of the ALTC funding was to 'promote and support strategic change in higher education institutions for the enhancement of learning and teaching' (The Australian Learning and Teaching Council, 2010, p.2). More specifically, curriculum renewal projects were expected to 'develop and model contemporary curricula that meet student and employer needs and provide the basis for on-going personal and professional development for students, p.5'. It was further suggested that curriculum renewal proposals should 'integrate content focussed discipline developments with learning and teaching innovations', (p.5). An Australian Learning and Teaching Council paper on curriculum renewal by 
Hicks (2009) recommended the curriculum framework developed by Barnett and Coate as suitable for Australian higher education. This framework was adopted as the primary approach for this curriculum renewal project. The initial curriculum design project had five institutional partners or collaborators. The renewed and nationally consistent curriculum for undergraduate youth work education in Australian universities was agreed in 2014 (Cooper et al., 2014).

After the renewed curriculum design was agreed, the next task was to make the changes necessary to existing courses so the expected benefits of the new curriculum could be realised in practice. Course coordinators at each of the partner institutions were responsible for leading these changes in their own universities. I received additional funding from my institution to support implementation of some parts of the renewed curriculum, in particular to revise online materials.

\section{Action-Learning Method}

An action-learning method was used for the curriculum implementation phase of the project. The action-learning method begins with the assumption that existing programmed knowledge is not always sufficient when faced with real-world problems in context (Pedler \& Evans, 2011). Cyclical inquiry processes of dialogical questioning, planning, observation, information gathering, reflection and re-questioning, learning and re-planning are needed both as a problem-solving method and as a learning support process for participants (Weinstein, 1998). The action-learning approach shares some similarities with grounded theory, in that the research process commences with examination of a process that occurs in a singular under-theorised real world example, and then discusses what was found in the context of the broader literature (Creswell, 2013). As such, the results are exploratory, and judgement is required about applicability of the findings to other contexts. Action-learning is a particular form of experiential learning (Weinstein, 1998) and also shares characteristics with the generalised approaches described in problem-based learning, such as the focus on real world open-ended problems to support learning and the value of shared group dialogical discussion as a method to develop insight (Savin-Baden \& Howell, 2004).

In accordance with the action-learning approach, first I will present the learning from implementation of a curriculum renewal process. Next, I will discuss how this experience relates to existing literature on curriculum, academic work and contemporary management practices in universities, to determine which aspects of learning are localised to the particular context, and which might have broader application. Finally, building from this discussion I make suggestions about how the experiences in this project may have implications for other academic staff who are planning to implement curriculum change, or for university managers whose role it is to support academic staff to implement curriculum change. The context will be described in sufficient detail to enable readers to decide the relevance of this analysis to their circumstances.

\section{The Study}

\subsection{Context of Curriculum Renewal Project}

The curriculum renewal process described here occurred at one university over a two-year period between 2013 and 2015. This permitted two complete action-learning cycles. The university is a large 'young' Australian public university established in 1991. It is located in a capital city and offers a comprehensive range of courses in on-campus, on-line and mixed delivery modes. The university has a strong reputation for teaching, and has received the highest possible rating for teaching quality for several consecutive years ("Good Universities Guide," 2017). As is common in Australia, most students studying on campus live locally and compute daily from home. Only a small proportion of the student population are residential on-campus, and these are mostly international students or students from regional or remote areas. The university has self-accrediting status under the Tertiary Education Quality Standards Agency (TEQSA), which means that the university has the authority to approve its own courses. In Australia, all self-accrediting universities receiving public funds are required to be audited every five years by TEQSA (Australian Government, 2012). Australian government higher education policy prioritises the role of universities in contributing to the economy and to expectations of students and employers, and these prioritises were reflected in earlier discussion of the parameters for the Australian Learning and Teaching Council funding for curriculum renewal.

Before commencing, some questions of terminology need to be clarified. In this study the term 'course' refers to the overall degree award, which is sometimes called the programme in other institutions. The term 'unit' refers to elements within the course, sometimes referred to as a module, subject, or course elsewhere. Casual staff are staff who are paid by the hour and have no employment security, and contract staff, are staff employed on fixed-term contracts (usually 6-12 months) who have no security beyond the duration of their contract. At the time of this project, the youth work course was staffed by one full-time permanent teaching and research academic, one temporary part-time teaching-only contract staff member, and four casual staff whose main employment was as professional youth workers. The project team also included part-time participation of a learning designer who provided support across several schools for development of the digital learning environment. 


\subsection{Curriculum Renewal and Implementation}

We commenced the curriculum renewal project with the intention of using Barnett and Coate's curriculum framework as our main curriculum methodology. All five sites in the national project had committed to this approach, and had agreed key elements of core disciplinary content. Staff at different institutions then completed detailed curriculum designs independently to suit their own circumstances. In our project we used a multi-layered approach. Barnett and Coate's framework was used to establish the overall curriculum orientation, and Threshold Concepts (Meyer \& Land, 2012) were used to prioritise and order essential disciplinary content. For the detailed organisation of learning experiences we used the Community of Inquiry framework (COI) (Garrison \& Arbaugh, 2007) to help with design of the digital learning environment. To align assessment we used the SOLO taxonomy (Biggs \& Tang, 2007). Finally, for quality improvement and staff learning we used an action learning approach (Boshyk \& Dilworth, 2010; Weinstein, 1998).

\subsection{Barnett and Coate's Framework}

The first framework we used for the project was Barnett and Coate (2005) curriculum framework, see figure 1. This framework established the overarching orientation to knowledge within all courses in the national project. Barnett and Coate (2005) contend that higher education curriculum should encompass three different types of learning: 1) 'knowing', or knowledge about; 2) 'acting', knowledge for action, or performative knowledge; and, 3) 'becoming', or how knowledge is integrated with the self, see figure 1. Barnett and Coate's framework was used to determine balance between types of learning (knowing, acting and becoming) across the course and within individual units. In their discussion of their framework Barnett and Coate suggest that for professional education the three domains of learning are likely to be balanced more or less equally. This was true for the overall course structure, whilst at unit level the emphasis varied between units.

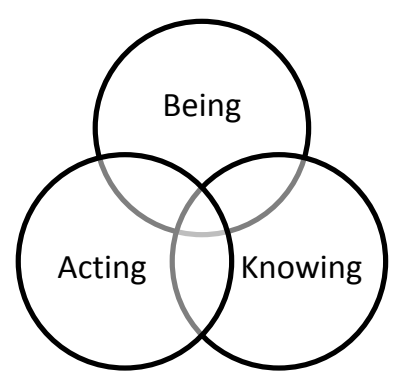

Figure 1. Barnett and Coate's curriculum framework

The orientation of Barnett and Coate's curriculum framework aligned well with the holistic purposes of youth work as a profession. For example, the youth work relationship is built on trust, with the expectation that youth workers will interact with young people as ethical and authentic human beings (Jeffs \& Smith, 2005). In this context, Barnett and Coate's curriculum orientation would propose that the curriculum should support students to integrate knowledge about ethics, with skills that embody ethical interactions, and ideally, knowledge about ethics and embodied skills become integrated with the self, so that youth workers become authentic ethical human beings. The Barnett and Coate curriculum framework is significant because their framework legitimates 'being' or 'becoming' as a valid purpose of the educational process. Banks (2010) argues following an Aristotelian approach to virtue ethics, that integration of ethics into self, or being, is a worthy aspiration for professional youth work education. She suggests that youth work education should support youth workers to become the kind of people who are ethical in their work with young people. A virtue-based approach requires integration between self, knowing and doing, and provides a rationale for the importance to youth work professional education of Barnett and Coate's domain of 'being'/'becoming'.

\subsection{Threshold Concepts}

Social realists such as Wheelahan (2010) and Young (2013) have argued for greater attention to discussions about the place of knowledge in curriculum. Accordingly we sought a process to make good decisions about what disciplinary content to include and what to leave out. As part of regular updating, new content is continually added to units each time they are taught. This is not always balanced by removal of an equivalent quantity of existing content, and over time, we have found that units often accumulate more content than can be taught. The staff team had already identified that some parts of the course had become "over-stuffed" with content and had become unwieldy to teach. We sought a curriculum process that would enable us to come to reasoned decisions about what content to prune. Barnett and Coate's (2005) framework allowed us to establish our overall orientation to curriculum, but did not provide guidance about 
priority and ordering of disciplinary content. To make a connection between the discipline and the curriculum, we used Threshold Concepts (Meyer, Land, \& Bailie, 2010). Threshold Concepts were used at unit level to identify the priority and sequence of conceptual learning. This approach was chosen because the focus was conceptual, which enabled the renewed curriculum to focus on how best to support students' understanding of the most difficult concepts that defined youth work as a field of study. In some cases, the application of this process completely changed the priorities and approach within a unit. Threshold Concepts also facilitated discussion between staff team members about how to prioritise and sequence learning materials.

The use of Threshold Concepts allowed us to articulate and sequence intended processes and outcomes in terms of conceptual learning at both a course and unit level. For example, in a first year unit, 'Youth Issues', the content had previously focused on presenting information about a range of topics relevant to young people, such as, school, work, spirituality, leisure, homelessness, drug and alcohol use, friendships and relationships, family and parents, health and crime. The original unit focussed upon the presentation of information about young people's experiences, but did not explicitly focus on information literacy or support students to develop their research skills. In the renewed curriculum, we changed the focus to information literacy and basic skills in assessment of information quality. One of the Threshold Concepts for the unit became: 'Differentiate between commonly held opinions about youth issues and 'research informed' understanding'. The focus of the unit changed to teaching students how to judge the quality of information about young people. This required them to know where to locate high quality youth research, to know how to differentiate between research findings and opinion, and to use this learning to make judgements about whether commonly encountered opinions were supported by good quality research. This change of focus made it easier for students to become more active participants in their learning and also provided general academic support that would be useful beyond this particular unit. At a time of ready availability of information, opinion and 'fake news', judgements about information quality are especially important, as is knowledge of how to locate reliable information and research.

\subsection{Guides to Pedagogy}

Threshold Concepts helped us to identify conceptual focus and sequence, but offered only limited guidance on pedagogy and organisation of learning experiences. The course we offer is available on-campus and in online mode. We looked to other frameworks to guide the development of learning materials, assessment, and the practical organisation of the teaching and learning environment. A modified version of the Community of Inquiry (COI) framework (Garrison, Anderson, \& Archer, 2010) was used to organise the digital learning environment and this is discussed in more detail in (Cooper and Scriven (2017). The SOLO taxonomy (Biggs \& Tang, 2007) was used to align the assessment with intended learning. These curriculum approaches had a subsidiary role in the curriculum design, and were used to implement curriculum decisions already made through the use of the Barnett and Coate framework and the Threshold Concepts approach.

\subsection{Action-Learning}

As a team we are reflective about our practice, and ideally we would fully adopt an action-learning model to evaluate and continuously improve our curriculum designs and to extend our own learning and professional development. However, practical constraints and especially time limitations meant that our implementation of the approach was less comprehensive than the model proposed by Weinstein (1998). We met less frequently than is ideally recommended, although we maintained regular communication in other ways. We used a variety of sources and methods to gain feedback about the effectiveness of changes we had made. We used data about student feedback, student progression and student retention provided by the institutional systems. We supplemented this with other data we gathered to provide a more comprehensive picture. We held meetings once a year to evaluate each unit and the course as a whole. These meetings were attended by all staff during the action-learning phase of the project, including the learning designer. While the new curriculum was being implemented and additional funds were available, casual staff were paid to attend these meetings. After the pilot project finished, they were not be paid, and we had to modify our process to consultation prior to the meetings. These factors limited the completeness of the formative evaluation processes we used and reduced opportunities for learning and staff development for casual staff. Table 1 summarises the contribution of each element of the layered curriculum approach. 
Table 1. Contribution of each element to the curriculum renewal process

\begin{tabular}{|c|c|c|}
\hline Purpose & Process & Contribution \\
\hline $\begin{array}{l}\text { Purposes of university } \\
\text { education }\end{array}$ & Barnett \& Coate & Maps purposes of education within course \\
\hline $\begin{array}{l}\text { Selection of learning } \\
\text { experiences }\end{array}$ & Threshold Concepts & $\begin{array}{l}\text { Identifies disciplinary Threshold Concepts; and sequence/ } \\
\text { distribution between units }\end{array}$ \\
\hline Organisation of learning & COI and SOLO & $\begin{array}{l}\text { Guides development of materials; Constructive alignment of } \\
\text { assessment; Climate for online and classroom learning }\end{array}$ \\
\hline Implementation & Curriculum-in-action & Timetabling, rooms relationships, dynamics, unforeseen events, \\
\hline Evaluation & Action-learning & $\begin{array}{l}\text { Action learning to find out how learning experiences contributed to } \\
\text { student learning }\end{array}$ \\
\hline $\begin{array}{l}\text { Learning and } \\
\text { improvement }\end{array}$ & Action-learning & $\begin{array}{l}\text { Find out where change is needed; staff learning and reflective } \\
\text { practice }\end{array}$ \\
\hline
\end{tabular}

\section{Learning from This Project}

The primary benefit of the multi-layered approach to curriculum renewal was that it helped us implement course changes, including what we taught, how we worked with students (pedagogy), how we evaluated our work and how we responded to evaluation. This latter point is significant because casual staff whose position is very tenuous sometimes become very despondent about student feedback, especially when the feedback seems unfair or unbalanced, and they have no voice to express their concerns and right of reply. The action-learning process allowed them to air their concerns and receive support. The process also encouraged all of us to think more deeply about what we were trying to do and how we could balance competing tensions, for example, between students' personal development needs, our responsibilities to the profession and our concerns for the young people with whom our graduates would work. Using Barnett and Coate's (2005) framework, we added more activities that helped students to make links between their university learning, their life experiences and their worldview. The Threshold Concepts approach enabled us to rethink the way we taught most units. In particular, we changed the teaching to focus on conceptual understanding of the most difficult key concepts. If we had relied solely on standard student feedback, we would not have made these changes because the student feedback for the previous course was within an acceptable range and did not point to problems with curriculum design, even though this was where change was needed. The Barnett and Coate curriculum framework and the Threshold Concepts approach enabled staff to be have input into the design process and to identify redundant content. We embedded academic skills into first year units and developed units to become more interactive on-campus and online. We aligned assessment with intended learning (Biggs \& Tang, 2007). We experimented with building student learning communities. Through dialogical group discussions, improvements were made to curriculum and some units became less stuffed with redundant content. All of us gained greater insight into alternative curriculum approaches and implementation possibilities, in a context that was immediately relevant to our interests and needs. This provided useful staff development for us all.

An unintended outcome was that we improved retention in the large first semester first year unit (to over $90 \%$ on-campus), even though the unit increased in size by 30\% during this period (from 102 to 134). The combination of curriculum frameworks provided a coherent rationale for changing the course orientation and practical guidance on how to achieve change. The use of multi-layered curriculum frameworks facilitated discussion with stakeholders, including the course consultative committee. The curriculum frameworks also helped us to evaluate the changes more comprehensively than the standard university processes, even though the action-learning process was less comprehensive than we ideally wanted.

\subsection{Barriers Identified}

We identified several barriers to implementation during the course of the project. The curriculum implementation required significant change and affected both pedagogy, and our interactions with institutional systems and practices. Documentary changes were needed so that the new curriculum was recorded correctly within institutional systems, and this meant re-writing all official course and unit documents. Pedagogic changes required revision of course materials and resources, and of the digital learning environment. Pedagogic changes also required us to educate students about the new approaches to learning and how they differed from their previous experience and expectations. Staff development was needed so all staff understood the intention of the new curriculum and could adjust the ways they taught. At a deeper level this involved discussion about the purposes of university education, the balance between the individual needs of students, responsibilities to the profession and disciplinary integrity. The approach we took to evaluation had 
implications for course improvement and for staff learning and development. The two main barriers we encountered were insufficient time to fully implement change, and tensions between the curriculum frameworks we used and the tacit curriculum embedded in university processes and practices.

\subsubsection{Lack of Time, Staffing Stability and Control}

Lack of time adversely affected all aspects of the project. Even though we received additional special funding, the implementation process still required more time than was allowed or could be paid for with additional funds. The additional funds were mostly used towards the development of new online materials, and to pay for development of the digital learning environment. A small amount was used to pay casual staff to attend review and development meetings. Even with additional funds, the resources were insufficient to allow full redevelopment of all units.

Apart from the project leader, none of the team were familiar with either Barnett and Coate's curriculum approach or Threshold Concepts before this project, and none of us had previously implemented curriculum explicitly based upon these approaches. Staff development was important so that all staff understood and supported the ideas behind the renewed curriculum, and so we knew how to change our practices to alter how students experienced the course. Formally, this professional development occurred through dialogue at meetings paid for through special funding. Informally, it occurred through many other channels, including conversations, phone calls and discussions that happened outside of paid time. This was important for successful implementation of curriculum change because the revised curriculum required changes to ways of seeing learning, teaching, assessment and materials. These changes required time for us to assimilate, to discuss our concerns, to work out implications for practice and to agree ways forward.

The redevelopment of learning materials raised a number of practical problems. Both Barnett and Coate's approach and the Threshold Concepts approach required substantial redevelopment of learning materials and pedagogy within each unit, as did the use of the COI approach for online learning. There were eleven core units in the degree and ideally these all needed to be revised so we could implement the curriculum fully. However, we directly controlled the content and delivery of only seven of these eleven units. The other four units were shared with other courses and three of these were taught by staff not involved in the curriculum implementation project. Any changes to content and delivery would need to be negotiated with the person responsible for the unit and with other course leaders. We decided to focus initially on the seven units where we had control. The tasks of redeveloping the unit materials could only be given to staff who had employment contracts for the whole period of the project, so the work of unit redevelopment had to be undertaken by the project leader who was the only team member with permanency.

The time taken for redevelopment of course materials in each unit was much greater than the time allowed in the institutional workload model. The workload model allocated 39 hours for major unit redevelopment, but we found the time taken was about 200-250 hours per unit, and this did not include time taken subsequent adjustments. These constraints meant we were not able to re-write all the required materials, and in some units only limited modifications could be made initially. Choices had to be made about which units to prioritise, and we chose to focus on the larger first year units, and the units where the differences between the old and the renewed curriculum were greatest. Overall the time taken for the implementation phase of the project was underestimated and we could not do everything within the time available for the task. Lack of permanent staff compounded this problem. Re-writing that was only partially completed or deferred had to be completed gradually, using time that should have gone to other tasks. So far, attempts to change the shared units have met with little success. This raises questions about whether we should develop replacement units that fulfil our curriculum purposes better, and highlights more general difficulties for maintaining relevance when units are shared between several courses.

\subsubsection{Explicit, Tacit and Embedded Curriculum Philosophies}

A second area of tension emerged during implementation between the philosophy and practices of the revised curriculum and the tacit curriculum assumptions embedded within existing institutional systems and practices. In this context, some of the barriers were embedded in the formal processes of institutional reporting systems. Other barriers emerged from practices that were built into the university infrastructure and support arrangements.

Tacit assumptions within institutional reporting systems created a number of barriers to fitting the new curriculum into institutional documentation systems. The tacit curriculum assumptions embodied in institutional course documentation and quality management systems had developed primarily in response to the reporting requirements of TEQSA. The reporting requirements were framed based upon positivist assumptions about knowledge and sought demonstrable evidence of student learning. The documentation assumed a rationalist neo-Tylerian approach to curriculum that embedded demonstrable learning outcomes as a key requirement. The most obvious incompatibility was between the 'becoming' domain of the Barnett and Coate framework, and the requirements of the standard documentation, because the course documentation template would accept only behavioural learning outcomes. This meant that although Barnett 
and Coate's domain of 'being' was centrally important to the youth work degree, it was impossible to include when course templates were completed, because it could not be captured by the listed behavioural learning outcomes without losing its essence.

Threshold Concepts could be incorporated into the unit descriptions template only if it is accepted that all conceptual learning is behaviourally demonstrable, an assertion which is contestable. It was impossible to use Threshold Concepts within the standardised system of demonstrable course learning outcomes (CLOs). This was because the standard template required CLOs to align with a list of generic institutional graduate attributes, each of which had to be linked to nominated assessment tasks. The map of course learning outcomes we developed using Threshold Concepts was much more detailed than the graduate attributes, but was too complicated to include within the institutional system. This meant that when we completed the institutional template, most of the real detail was lost. As a result, the emphasis presented in the official CLO document no longer matched the emphasis in our own curriculum documents.

A mismatch between the curriculum requirements and institutional facilities and practices can also act as a barrier to successful curriculum implementation. Universities decide how they will provide student support services, rooms, equipment, technical support services and other facilities, all of which are important to the enacted curriculum. Academics usually have minimal input into how these services are organised. Some ways of organising ancillary functions align best with particular curriculum approaches. For example, if the curriculum is designed for interactive discussion, it is easier to implement effectively if the class is timetabled to occur in a room arranged for discussion rather than a tiered lecture theatre with fixed seating. We were fortunate that in most instances, rooms allocated were appropriate to the teaching approaches we were using. When this does not occur, this affects the students' experiences of the curriculum. Room availability and uncertainty about likely class sizes, means that these preferences cannot always be respected when classes are timetabled. The timing of classes is also allocated by timetabling staff, who optimise room usage. Some of the allocated times may make it difficult for students to attend. This can be a problem for example, if classes are scheduled in the evening, and student and staff services close late afternoon, or if many students rely on public transport, which is less frequent in the evenings. Unless there is a good alignment between the curriculum approach used in teaching and facilities that support teaching and learning, these factors may detract from the curriculum as enacted by staff and as experienced by students.

The quality management arrangements did not pose a barrier to implementation of change, but contributed to an environment that imposed a particular understanding of educational quality. The epistemic assumptions of our curriculum process were in tension with the epistemic assumptions of the institutional quality management system. The quality management system instituted by the university was develop to ease reporting to TEQSA, and as mentioned the TEQSA system tacitly assumed a positivist orientation to knowledge. This system focused upon collection and analysis of relatively easy to collect quantitative data, such student progression, distribution of student grades, and student feedback. This information is useful but incomplete and one-sided. Student feedback is presented primarily in quantitative in format. From a positivist orientation, students are assumed to be customers, notwithstanding the problems with this assumption (Cooper, 2002a), and student satisfaction and student retention are conflated with quality measurement, ignoring the complexity of these relationships (Cooper, 2002b). This is especially problematic when data are summarise numerically, and can lead to simplistic and irrational data usage, as illustrated when an unthinking (or statistically-challenged) manager voiced the expectation that all unit evaluation scores should be numerically above the average for the school and the university. Simplistic data analysis, in an environment where academics fear adverse consequences of below average scores, can inhibit experimentation and change.

The standard institutional evaluation processes undervalues the importance of the integrity of educational processes. The focus on student retention, progression and satisfaction, deflects consideration away from what students have learnt as they happily progress. The assessment process does not recognised that it is sometimes necessary challenge students' pre-existing expectations about education. From a social constructionist orientation to knowledge, students' perceptions are of interest and help teachers gain a better understanding of students' worldview, but they should not be used simplistically as a proxy for judgements about quality. During the action learning process we added staff feedback about processes and materials, additional student feedback about what they had learnt, analysis of sample assignments, and review of resources and materials. In staff meetings, all staff were asked about their perceptions on all aspects of the learning and teaching processes, and what concepts or other aspects of learning needed to be improved. In addition, if there appeared to be problems in a particular unit, we gathered additional data from students about aspects of the course that required attention. There was no funding to maintain additional evaluation beyond the initial period, and no funding was available to pay casual staff to attend the meetings. As a consequence, opportunities for both quality improvement and staff development were diminished after the project finished. Barriers to curriculum implementation are summarised in Table 2 . 
Table 2. Critical tensions

\begin{tabular}{|c|c|c|}
\hline Purpose & Process & Critical Tensions \\
\hline $\begin{array}{l}\text { Purposes of university } \\
\text { education }\end{array}$ & Barnett \& Coate & Institutional template performative vs. 'being' is not performative \\
\hline $\begin{array}{l}\text { Selection of learning } \\
\text { experiences }\end{array}$ & Threshold Concepts & $\begin{array}{l}\text { Concepts did not map onto graduate attributes, and granularity was } \\
\text { lost }\end{array}$ \\
\hline Organisation of learning & COI and SOLO & Time required much greater than time allowed \\
\hline Implementation & Curriculum-in-action & $\begin{array}{l}\text { Requires suitable rooms; technology support, and ancillary student } \\
\text { support, but these are not under academic control }\end{array}$ \\
\hline Evaluation & Action-learning & $\begin{array}{l}\text { Standard process tacitly reinforces a customer-like relationship/ } \\
\text { transactional model of education }\end{array}$ \\
\hline $\begin{array}{l}\text { Learning and } \\
\text { improvement }\end{array}$ & Action-learning & $\begin{array}{l}\text { No payment for casual staff; data insufficient; time; difficult to } \\
\text { change shared units }\end{array}$ \\
\hline
\end{tabular}

Some of the curriculum changes we made were substantial, and not all worked as well as we hoped the first time they were implemented. A comprehensive embedded improvement process across two cycles of course delivery was the absolute minimum necessary for implementation. For fine-tuning, more cycles would be better. In several instances we were still making adjustments at the third iteration, and this will continue. Although the institutional quality improvement system incorporates elements of action learning, the range of standard data collection was not sufficient to diagnose what needed to be changed or the efficacy of changes made, and was skewed toward easy to collect data rather than what was most useful. As a counter-balance, the staff meetings have been very important. It would be beneficial for both quality improvement and staff development, if participation one annual face-to-face staff meeting could be supported financially to include all staff, including casual staff and where relevant learning design staff.

\section{Discussion}

In this section of the article, the focus is firstly to determine whether the experiences identified in this project have broader application, or whether they are just localised occurrences without importance beyond their context. Secondly, literature will be used to inform understanding of the findings from this study in the context of other research and changes within the university sector.

\subsection{Universities and Curriculum}

Authors discussing curriculum in higher education frequently commence with two observations. Firstly that only rarely is the term curriculum is used explicitly in higher education (Barnett \& Coate, 2005; Dillon, 2009; Hicks, 2007) and secondly, that the concept of curriculum is contested and used in many different ways (Barnett \& Coate, 2005; Dillon, 2009; Hicks, 2007; Marsh, 2004). I will now discuss the implications of these observations for understanding our experience in this project.

The infrequent discussion of curriculum in Australian higher education is illustrated in a review of the higher education curriculum renewal programme conducted by the Australian Learning and Teaching Council (ALTC). Hicks (2009, p. 4) noted that in funding requests received by the ALTC under the curriculum renewal program, 'there was little recourse to literature on curriculum'. This was surprising because the funds were provided exclusively for curriculum renewal.

Diminished discussion of curriculum in Australian higher education has permitted the tacit concept of curriculum embedded in TEQSA expectations to be integrated into university reporting systems, without discussion about the educational consequences that flow from this particular curriculum approach. The tacit understanding of curriculum that informs TEQSA reporting, allows curriculum design to be presented as an atheoretical undertaking concerned only with low-level ends-and-means linkages, and separated from ideological discussions about the purposes of education. Priestley (2011), argues that

'At the meso- and micro-levels of curriculum enactment, an atheoretical perspective potentially denies local policy makers and practitioners the conceptual tools to make sense of policy, and engage with local needs and contingencies in a manner that is educational.' (p.227)

In our context, intellectual discussion about the nature of university learning was restricted by the focus on the micro-levels of curriculum enactment. As a consequence, is was permissible to discuss how student learning can be expressed behaviourally, but not permissible to ask whether the assumption that all university learning can be behaviourally described should be accepted, or whether and how exceptions might occur. Since all Australian public universities operate in the same regulatory environment, it can be surmised that our experiences are not unique in 
Australia. Our experiences may also be relevant in other countries where education systems operate under similar regulatory arrangements.

The literature on curriculum illustrates that there are multiple definitions of curriculum and the bounds of the concept are contested. As Dillon observes, the different usages are not mutually consistent (Dillon, 2009).

'Taken as an ensemble the definitions and conceptions of curriculum are known to be incoherent, and by individual contrast to be divergent when not contradictory. It has become obligatory, as in textbooks, to display a dozen or more answers in all their diversity, to almost no purpose or effect other than to dispirit the reader' (p. 344).

Accordingly, I will not engage here with this types of discussion beyond acknowledging that curriculum theorists disagree about many things, including: underlying discipline (educational psychology or sociology or cultural studies); bounds of the concept (does it include pedagogy or not?) and the relationship between curriculum, educational theory and power. Philosophically Barnett and Coate's framework falls within critical curriculum (Apple, 2004), where discussion about curriculum includes discussion of the nature of knowledge, and the relationship between education and power, as well as the design and organisation of learning experiences, and its relationship to pedagogy.

\subsubsection{Problems with Behavioural Learning Outcomes}

There is a growing literature on curriculum and learning outcomes and diverse perspectives on how learning outcomes should be defined and used (Allan, 1996; Biggs \& Tang, 2011; Blömeke, 2013; Coates, 2014; Shupe, 2007). Behavioural learning outcomes embedded in the institutional reporting systems were problematic for the implementation of our project, so here I am focusing on the particular problems with behavioural learning outcomes. Allan (1996) distinguishes between the use of learning outcomes, which she argues must include non-behavioural elements and may be composite in nature, and behavioural learning outcomes, which she rejects because

'The requisite of precise observable objectives in rational curriculum design precludes the planning of earning experiences for which the outcome cannot be pre-stated at a level of specificity capable of being translated into clear-cut behaviours which are capable of being measured and assigned with an indication of what constitutes an acceptable standard of performance in a given context. The reductionist thinking which results from such a prescriptive approach imposes a strait-jacket on curriculum planning; this is the major source of criticism of behavioural objectives...' (p. 96).

She concludes that higher education must abandon the requirement of behavioural descriptors for learning outcomes, and in doing so, must 'shed the mantle of behaviourism which is antithetical to higher education, (p.97)'. This concurs with the difficulty we experienced when we tried to fit our curriculum into a template based on behavioural descriptors.

Behavioural learning outcomes are unsuited as a basis for university learning because they do not encompass any educational processes where the precise outcome is open-ended, cannot be predicted, or may vary between students. For example, based upon Threshold Concept principles, in our curriculum we had very clear ideas of the key concepts that are central to each unit. These constitute the intended learning outcomes for the students. In teaching, we apply a range of strategies to support students to understand these key concepts. We present, reinforce and consolidate important ideas in a variety of different ways throughout our teaching. Some students grasp key concepts more quickly than others. For those students who have grasped the key ideas quickly, within our teaching we always include some materials that will extend students further. For students in the same class who are still struggling with basic concepts, we find alternative activities that support their learning at a more basic level. By the end of the unit, some students will have gone well beyond the basic concepts stated in the learning outcomes, either with our support or on their own initiative, whilst others may still be grappling to fully understand ideas they find particularly difficult to grasp. We do not always fail a student who is still struggling with a difficult concept, as sometimes conceptual learning takes longer to fall into place. Learning outcomes can encompass this difference, but behaviourally learning outcomes cannot.

Both Barnett and Coate (2005) and Knight (2001) argue for the importance within curriculum of space for fluidity and flexibility. In addition, educators from various curriculum orientations, including critical pedagogy (Freire, 1972), experiential perspectives such as Dewey (1938) and even rationalist approaches such as Tyler (1986) are responsive to the varying needs of students. Although Tyler promoted the rationalist curriculum, according to Allan (1996) he did not conceptualise all outcomes as behavioural because he included feeling and thinking as outcomes of learning. Any approaches that adjust teaching to local opportunities and particular needs cannot be fully encompassed within the framework of predicted behavioural outcomes of learning specified in advance. From any perspective, a curriculum orientation for higher education that inhibits learning that is unforeseen or unmeasurable appears to be overly restrictive.

In the critical curriculum literature various examples are found where academics discuss how university systems distort curriculum. In the UK, Barnett and Coate (2005) describe the tacit processes embedded into university systems as 
'curriculum by stealth', because the assumptions behind the system are taken for granted, are assumed to be incontestable, and are not open to discussion or debate. This aligns with our experience, where we had to distort the representation of our curriculum to make it fit into the reporting templates. The curriculum approach we used assumed a social constructionist view of knowledge, but the representation in the official documentation had a positivist orientation to knowledge, which introduced a distortion. Similarly, our approach to evaluation was constructivist, but the institutional process was tacitly positivist, introducing a second layer of misrepresentation. This is problematic, because if a curriculum approach assumes a social constructionist perspective on knowledge, it cannot be fairly represent or evaluated within positivist epistemology.

\subsection{Academic Work and Curriculum}

Our project touches upon discussions about the nature of academic work in three distinct ways. Firstly, with respect to the impact of staff contractual arrangements, secondly with respect to time pressure and work intensification, and thirdly with regard to staff development, qualifications and expected knowledge. All these areas have implications for the ease, or difficulty of implementation of curriculum change, and how processes of had to be adjusted to accommodate these realities.

\subsubsection{Temporary Staff Contracts}

In contractual terms, the staff project team of six included only one full-time permanent, tenured staff member on a 'traditional' academic teaching and research contract. One staff member was employed on a series of part-time fixed-term contracts, and four staff were casual part-time staff whose main employment was as professional youth workers. The learning designer was also employed on a fixed-term contract at the time of the project. Excluding the learning designer who was employed centrally, the staff team was equivalent to about 2.5-3.0 staff in total, varying between semesters. Compared with aggregate Australian data, our program made greater use of temporary and casual staff than was typical at the time (Tertiary Education Quality Standards Agency, 2015). Increased casualization of academic work has been confirmed as a trend in Australia and globally since at least the 1990s (Bryson, 2004; Kimber, 2003; May, Strachan, \& Peetz, 2013). Kimber accepts that casual staff may help to maintain professional and industry links, but argues that losses are incurred because casual staff are excluded from decision-making within the university. These observations align with the findings from our project. She argues further that there are hidden costs to casualization, including contractual expenses, poorer staff access for students and staffing insecurity as those who can leave, often do so. Our experience accords with these observations. May et al. (2013) also found that even when casual staff were invited to staff meetings and staff development, most were not fully paid for their time, so the practices found in our example were not uncommon. Since the project finished we have managed to increase the number of staff on permanent contracts from one to three (2.8 full-time equivalent). One staff member is still on a casual contract, in line with his preference, and two casual staff have left. Gaining more permanency for staff has increased stability and meant that staff who have gained skills through the action-learning project have been retained. This arrangement also means that the tasks of revising curriculum materials can now be shared across a greater number of staff.

\subsubsection{Workload Models and Time Allocation}

A second area of concern about academic work in our project was shortage of time to complete tasks necessary for full curriculum implementation. Interestingly Tyler (1986, p. 21-22) reflecting upon his eight-year study conducted in the 1930s noted that curriculum implementation and associated professional development was very time consuming.

'In connection with the time issue relative to curriculum development, I should mention that we found this integration of curriculum development and teacher education also required a great deal of time. This was the purpose of the summer workshops we held with teachers....Usually the workshops were at least six weeks in length so we could get something done; they were not casual encounters.' (pp.20-21).

Our experience aligns with Tyler's observations about time required. However, we found that this was not recognised in university workload calculation models used for academic work allocation and performance management purposes. Papadopoulos (2017) found that university workload models and metrics routinely underestimated the time required for high quality teaching. Papadopoulos also found that the administrative workload of many academics had also increased beyond the time allowed in workload models. Both these findings accorded with our experience. Other researchers interested in academic work have noted trends towards work intensification (Bryson, 2004; Kenny, 2017). Academic work intensification has reduced academic self-determination and control over discretionary time-use, and has increased performativity in academic work, even when staff have tenure (Kenny, 2017). As performativity measures have mostly focused on research outputs (Kenny, 2017), it could be conjectured that self-interested staff would direct any discretionary time towards research outputs rather than curriculum related activities, whilst according to Papadopoulos, staff interested in teaching would already be spending excess time on their routine teaching and administrative activities. In other words, our experience of having insufficient time available for implementation of curriculum change is 
consistent with contemporary Australian research on academic work intensification and may have resonance internationally. Insufficient time to implement the curriculum changes completely was a significant threat to successful curriculum change.

\subsubsection{Staff Development}

Finally, in our example, there was a strong focus on informal staff development as a necessary component of curriculum change. In terms of qualifications and experience, all staff except the learning designer had at least Bachelor qualifications in youth work and extensive professional youth work experience. Additional to these basic qualifications, two staff also had qualifications and professional experience in social work, the project leader had a PhD and formal qualifications in education, and some staff had graduate qualifications or were enrolled in higher degrees. Apart from the project leader, other staff had learnt about teaching on the job, supplemented by short teaching induction courses rather than through formal study. According to the literature, the lack of formal teaching qualifications for staff in Australian universities is not uncommon. Hugo and Morriss (2010) found that in Australia, there were two pathways to academic teaching. The first was through a $\mathrm{PhD}$, which they said was increasing being viewed as the basic qualification for academic work, although Hugo and Moriss questioned how well this prepared academic staff for teaching. The second pathway was through a Bachelor's degree plus extended professional experience, as is required for teaching many professional courses. This may be supplemented by concurrent part-time study towards a PhD. In accordance with Hugo and Moriss's research, the qualifications and experience of our staff team were not atypical for a professional course. Wahlén (2002) also found that formal education qualifications were uncommon amongst academic staff and suggested that formal qualifications for academics in teaching roles would benefit teaching quality. This also implies that, as in our circumstances, staff development whether by action-learning or by other means, is likely to be a beneficial and necessary component of curriculum implementation in other universities.

\section{Conclusions and Recommendations}

Our main conclusion is that integrated institutional support for curriculum implementation is essential to successful curriculum change. The price of not doing this is that higher education curriculum will become too difficult to change and this will amplify disconnection between university courses and advances in disciplinary knowledge, in educational theory and practices, and also changing economic, social and public good requirements. Learning from this project and relevant literature, suggests that successful curriculum change requires several different types of institutional support.

\subsection{Proper Recognition of Complexity of Curriculum Renewal and Time Taken}

Firstly, there needs to be proper recognition of the complexity of the task and the time taken for completion of all tasks that are integral to successful curriculum renewal. In a system of hourly workload allocation, as is currently normalised in Australia, this means that the real time taken to complete these tasks must be acknowledged and built into staff workloads. The extent of the work necessary for curriculum renewal also needs acknowledgement. It includes not only the creation of new materials, but also changes to the digital platform, changes to course documentation, changes to assessments, and support for staff learning development so the new approach well understood and supported.

\subsection{Importance of Staffing Stability}

Secondly, temporary staff contracts increase difficulty of implementing curriculum change because they threaten continuity. Staff continuity is needed so that the workload of curriculum redevelopment can be shared and to ensure that staff development effort is not wasted. Action-learning project teams that operate over multiple cycles, require employment security so that knowledge of the new curriculum approach can built over time. Ideally, most staff should be permanent to achieve stability and knowledge retention. If casual staff are employed it would be beneficial if they received payment to attend meetings and participate in the annual review processes.

\subsection{Action-Learning for Staff Development}

Thirdly, given that most academic staff have not competed formal studies in education (except where their discipline is education), action-learning provided a very useful and cost-effective staff development approach. This could be supplemented by other formal and informal staff development methods including, peer-mentoring for teaching, informal collegial discussions, non-line supervision, collaboration with the learning designer, and where appropriate, attendance at short courses. Flexible collaboration between the team and the learning designer supported the transfer of knowledge about digital learning and technology, and also provided practical help to make best use of the digital learning environment. This was a necessary component of success.

\subsection{Leadership}

Fourthly, leadership was important to the curriculum implementation process. The project leader required diverse leadership skills to work effectively and flexibly with the staff team and with others in the university whose support was 
needed. To be effective, the person leading the project required both disciplinary knowledge and a formal knowledge of theory in education, teaching and curriculum. Knowledge of education theory was essential to combine curriculum methodologies coherently, and curriculum design should be recognised as a specialist skill akin in complexity to skilled research design. Staff who have this knowledge are able to mentor and support the informal learning of their colleagues through a variety of processes, including action-learning. Knowledge of university reporting systems and possible sources of support was also needed to manage the compliance system within the university, and to build support for project from those working in other university centres, like timetabling, student recruitment, and student information services whose work has the capacity to help or hinder curriculum implementation, and to gain additional resources.

\subsection{Flexible and Supportive University Systems}

Fifthly, university systems at all levels need to be sufficiently flexible to encourage on-going curriculum renewal and experimentation with alternative curriculum approaches. Many of the university compliance processes are driven by the need to facilitate external reporting requirements. A key problem for university management is to find ways to buffer these requirements so that processes do not become so cumbersome or rigid that they stifle change. It is acknowledged that this is not easy. In our project we found some degree of flexibility. By adopting the Barnett and Coate (2005) framework we were able to identify what was missing from the conception of curriculum that implicitly informed the institutional processes and had shaped our previous practice. We also had a formal basis for contesting the universal adequacy of behaviourally specified learning outcomes for the purposes of our course. Although we have not been able to change the institutional system, we have been able to specify a broader purpose, and currently this co-exists uneasily within the formal system.

\subsection{Awareness of Context}

Finally, an awareness of our context helped us to consider proposed changes in the broader environment. Rarely is a single academic in a position to significantly change the environment within which they work or the environment beyond their work. We were able to identify the barriers in our context and make strategic decisions about where change was possible, where we needed to agitate for change, and where change was blocked for the time being.

\section{Acknowledgements}

Support for this project has been provided by the Australian Government Department of Education and Training through the Office for Teaching and Learning (formerly Australian Learning and Teaching Council) under grant number PP10-1612. Edith Cowan University supported curriculum implementation under the Strategic Initiative Fund, 2014. The views in this article do not necessarily reflect the views of the Australian Government Department of Education and Training or Edith Cowan University.

\section{References}

Allan, J. (1996). Learning Outcomes in Higher Education. Studies in Higher Education, 21(1), 93-108. https://doi.org/10.1080/03075079612331381487

Apple, M. W. (2004). Ideology and Curriculum. New York: Routledge Falmer.

Australian Government. (2012). About TEQSA. Retrieved from http://www.teqsa.gov.au/about

Banks, S. (2010). Ethics and the youth worker. In S. Banks (Ed.), Ethical issues in youth work. New York: Routledge.

Barnett, R., \& Coate, K. (2005). Engaging the Curriculum in Higher Education. Maidenhead: Open University Press and McGraw Hill Education.

Biggs, J. B., \& Tang, C. (2007). Teaching for Quality Learning at University (3rd ed.). London: Society for Research into Higher Education.

Biggs, J. B., \& Tang, C. S. K. (2011). Teaching for quality learning at university: what the student does (4th ed.). Maidenhead, Berkshire, England: Open University Press.

Blömeke, S. (2013). Modeling and measuring competencies in higher education: tasks and challenges. Rotterdam: Sense Publishers. https://doi.org/10.1007/978-94-6091-867-4

Boshyk, Y., \& Dilworth, R. (2010). Action Learning (pp. 320). Basingstoke: Palgrave Macmillan. Retrieved from https://doi.org/10.1057/9780230250734

Bryson, C. (2004). What about the workers? The expansion of higher education and the transformation of academic work. Industrial Relations Journal, 35(1), 38-57. https://doi.org/10.1111/j.1468-2338.2004.00299.x

Coates, H. (2014). Higher education learning outcomes assessment: international perspectives. Frankfurt am Main: Peter Lang GmbH. 
Cooper, T. (2002a). Concepts of 'Quality': and the problem of 'customers', 'products', and purpose in higher education. In A. Goody, J. Herrington, \& M. Northcote (Eds.), Quality Conversations: 2002 Annual International Conference of the Higher Education Research and Development Society of Australasia (Vol. 25, pp. 144-151). Canberra: Higher Education Research and Development Society of Australasia.

Cooper, T. (2002b). Why Student Retention Fails to Assure Quality. In A. Goody, J. Herrington, \& M. Northcote (Eds.), Quality Conversations: 2002 Annual International Conference of the Higher Education Research and Development Society of Australasia (Vol. 25, pp. 152-158). Canberra: Higher Education Research and Development Society of Australasia.

Cooper, T., \& Scriven, R. (2017). Communities of inquiry in curriculum approach to online learning: Strengths and limitations in context. Australasian Journal of Educational Technology. doi:https://doi.org/10.14742/ajet.3026

Cooper, T., Bessant, J., Broadbent, R., Couch, J., \& Edwards, K. (2014). Australian Youth Work Education: Curriculum Renewal and a Model for Sustainability for Niche Professions Canberra.

Creswell, J. W. (2013). Qualitative Inquiry: Choosing amongst five approaches. Thousand Oaks: Sage.

Dewey, J. (1938). Experience and education Retrieved from http://ruby.fgcu.edu/Courses/ndemers/Colloquium/ExperiencEducationDewey.pdf

Dillon, J. T. (2009). The questions of curriculum. Journal of Curriculum Studies, 41(3), 343-359. https://doi.org/10.1080/00220270802433261

Freire, P. (1972). Pedagogy of the oppressed. New York: Herder and Herder.

Garrison, D. R., \& Arbaugh, J. B. (2007). Researching the community of inquiry framework: Review, issues, and future directions. The Internet and Higher Education, 10(3), 157-172. https://doi.org/10.1016/j.iheduc.2007.04.001

Garrison, D. R., Anderson, T., \& Archer, W. (2010). The first decade of the community of inquiry framework: A retrospective. The Internet and Higher Education, 13(1-2), 5-9. https://doi.org/10.1016/j.heduc.2009.10.003

Good Universities Guide. (2017). Retrieved from https://www.gooduniversitiesguide.com.au/

Hicks, O. (2007). Curriculum in higher education in Australia - Hello? Paper presented at the Enhancing Higher Education, Theory and Scholarship, Proceedings of the 30th HERDSA Annual Conference Adelaide.

Hicks, O. (2009). Report on the Proposals and Expressions of Interest from the First Call for Priority Projects Grants Under the 'Curriculum Renewal' Priority, 2008 Retrieved from Sydney: http://www.olt.gov.au/system/files/Analysis\%20of\%20\%20CR\%20applications\%20Hicks\%202009.pdf

Hugo, G., \& Morriss, A. (2010). Investigating The Ageing Academic Workforce: Stocktake Retrieved from Adelaide, Australia: http://www.hru.uts.edu.au/docs/forum/hugo_morriss.pdf

Jeffs, T., \& Smith, M. K. (2005). Informal Education: Conversation, Democracy and Learning: Educational Heretics Press.

Kenny, J. (2017). Academic work and performativity. Higher Education, 74(5), 897-913. https://doi.org/10.1007/s10734-016-0084-y

Kimber, M. (2003). The Tenured 'Core' and the Tenuous 'Periphery': the casualisation of academic work in Australian universities. Journal of Higher Education Policy and Management, 25(1), 41-50. https://doi.org/10.1080/13600800305738

Knight, P. T. (2001). Complexity and Curriculum: A process approach to curriculum-making. Teaching in Higher Education, 6(3), 369-381. https://doi.org/10.1080/13562510120061223

Marsh, C. J. (2004). Key Concepts for Understanding Curriculum (3 ed.). Hoboken: Taylor and Francis. https://doi.org/10.4324/9780203326893

May, R., Strachan, G., \& Peetz, D. (2013). Workforce Development and Renewal in Australian Universities and the Management of Casual Academic Staff. Journal of University Teaching and Learning Practice, 10(3).

Meyer, J., \& Land, J. (2012). Overcoming barriers to student understanding: Threshold concepts and troublesome knowledge London: Routledge.

Meyer, J., Land, R., \& Bailie, C. (2010). Threshold Concepts and Transformational Learning. Rotterdam: Sense Publishers.

Papadopoulos, A. (2017). The mismeasure of academic labour. Higher Education Research \& Development, 36(3), 511-525. https://doi.org/10.1080/07294360.2017.1289156 
Pedler, M., \& Evans, R. (2011). ABC of Action Learning. Farnham, UK: Ashgate Publishers

Priestley, M. (2011). Whatever happened to curriculum theory? Critical realism and curriculum change. Pedagogy, Culture \& Society, 19(2), 221-237. https://doi.org/10.1080/14681366.2011.582258

Savin-Baden, M., \& Howell, C. (2004). Foundations of Problem-based Learning. Berkshire, UK: McGraw-Hill Education.

Shupe, D. (2007). Focusing the institution on student learning outcomes. Bradford, England: Emerald.

Tertiary Education Quality Standards Agency. (2015). Statistics report on TEQSA registered higher education providers. Retrieved from Canberra:

http://www.teqsa.gov.au/sites/default/files/publication-documents/StatisticsReport2013TEQSAHEProviders.pdf

The Australian Learning and Teaching Council. (2010). Priority Projects Program: Guidelines and Supporting Information -2010 Version 2.0. Sydney: Commonwealth of Australia.

Tyler, R. W. (1986). Reflecting on the Eight-Year Study. Journal of Thought, 21(1), 15.

Wahlén, S. (2002). Teaching Skills and Academic Rewards. Quality in Higher Education, 8(1), 81-87. https://doi.org/10.1080/13538320220127470

Weinstein, K. (1998). Action Learning: A Practical Guide. Abingdon, UK: Ashgate Publishing Ltd.

\section{Copyrights}

Copyright for this article is retained by the author(s), with first publication rights granted to the journal.

This is an open-access article distributed under the terms and conditions of the Creative Commons Attribution license which permits unrestricted use, distribution, and reproduction in any medium, provided the original work is properly cited. 